Title: What do we know about University Academics' Mental Health?

A Systematic Literature Review

\author{
Dr. Angel Urbina-Garcia, \\ University of Hull
}

Angel Urbina-Garcia, School of Education and Social Sciences, University of Hull.

Correspondence concerning this article should be addressed to Angel Urbina-Garcia, School of Education and Social Sciences, University of Hull, Cottingham Road; HU6 7RX. Email: M.Urbina-Garcia@hull.ac.uk Tel: 01482603019

Declaration of interest: The author confirms that there are no conflicts of interests with this piece of research.

This manuscript has not been published elsewhere and it is not being considered for publication elsewhere.

Acknowledgements: This study was not funded

\title{
What do we know about University Academics' Mental Health? A Systematic Literature Review
}

\begin{abstract}
There has been a growing interest on the negative influence that the environment of higher education institutions has on the mental health of academics. The current climate of global education-competition, places extreme expectations on academics. A number of factors
\end{abstract} through the copyediting, typesetting, pagination and proofreading process which may lead to differences between this version and the Version of Record. Please cite this article as doi: $10.1002 /$ smi.2956 
influence academics’ mental health, such as teaching, supervising, generating research income, among others, and there is evidence to suggest that the university environment is jeopardising academics’ physical and psychological health. This study sought to review the international literature with a view to ascertaining what the most commonly used measures are to investigate this topic, including the main stressors and coping strategies reported/used by academics and their lived experiences. A thorough review of the literature was conducted, and 28 studies were identified and critically analysed. The review concludes that there is compelling evidence that the university environment is triggering high levels of stress and burnout and low levels of wellbeing for academics. There is extremely limited research on the perceptions and lived experiences of academic staff. It is virtually unknown, what coping strategies academics use to face job demands, and our knowledge about burnout, seems to be limited by the use of one particular measure without cultural adaptations. Practical implications and directions for future research are proposed.

Keywords: Academics’ mental health, psychological wellbeing, stress, staff wellbeing, systematic review. 


\section{Introduction}

A study including 28 European countries focused on the working conditions and workers' health (Eurofund, 2019), reveals that work intensity (derived from a constant exposure to adverse demands) and workers' emotional demands (leading to emotional exhaustion which is an indicator of burnout) have increased in the last 10 years, which importantly, have been found to have a direct impact on workers' health and wellbeing. Particularly in the case of university academics, a recent review by Kinman and Johnson (2019), emphasises the rapid changes in the university sector over the last 20 years. These changes have led to numerous studies which have revealed a number of factors which are particularly hazardous to well-being such as teaching pressures, heavy administrative burden, research pressures and unsatisfactory leadership and management among others (see Barkhuizen, Rothmann, \& van de Vijver, 2014; Coulthard \& Keller, 2016; Guthrie et al., 2017). In fact, it is argued that there is an important shift in modern universities which are going from a teaching-led to a business model (Padilla \& Thompson, 2015). One possible explanation is that the international labour market is demanding more skilful professionals, with more professional degrees and experience, to feed the interests and needs of big transnational corporations around the globe (Cohen, 2018). These huge demands from big corporations, institutions and global organisations, are in turn placing incredible pressure on the higher education sector to produce more and more "trained" professionals, without acknowledging the side effects of this tendency. This social phenomenon has led some universities (albeit not all of them) to become consumer-led and profit-led organisations (Duderstadt, 2009; Rae, 2010), which has placed more pressure on students and academics. In fact, evidence suggests 
that students and academics are being affected by these demands, with increasing evidence that this impact is on their mental health and their productivity (Kinman \& Johnson, 2019; Watts \& Robertson, 2011). Specifically regarding academics, an increasing body of research has shown that this is a population particularly prone to developing mental health problems (Guthrie et al., 2017; Padilla \& Thompson, 2016; Shin \& Jung, 2014). Research shows that current job characteristics and working conditions lead academics to develop burnout syndrome (Schaufeli, 2013; Watts \& Robertson, 2011), which decreases their well-being (Richards, Andrew \& Levesque-Bristol, 2016), decreases their job satisfaction and increases ill health (Hurtado et al. 2012; Winefield et al. 2008). Interestingly, most of the literature seems to focus on investigating the impact of workplace-related factors on academics' mental health from a positivist approach -which according to Holts and Odag (2018, p. 3), this approach states that "the truth [...] can be broken down into separate observable and quantifiable entities that exist independent of human perception"-, which has indeed shed light on the levels of mental health of academics around the world. However, scholars have not critically analysed the main stressors, the prevalence of instruments used so far, and how academic demands are being perceived from a phenomenological perspective (the study of structures of consciousness as experienced from the first-person point of view; Gutland, 2018) by academic staff. This warrants efforts to develop a more comprehensive understanding of the adequacy of the methods used so far, and establish what the main environmental factors are, and how academics are coping with such demands.

To our knowledge, there are no reviews of the literature analysing what the most commonly used instruments/measures are, and what the main stressors and coping strategies 
used by academics are. Our initial review of the literature found only four studies in this regard (Salimzadeh, Saroyan \& Hall, 2017; Tai, Ng \& Lim. 2019; Yusoff \& Khan, 2013; Watts \& Robertson, 2011), however they have several limitations. These studies did not analyse methods used to capture the whole spectrum of mental health of academics (i.e., academics' lived experiences, perceptions, attitudes etc.). Data were limited to just a few locations (i.e., Pakistan and Malaysia), some are almost ten years old and some did not consider qualitative studies. The present study is vitally important, since a synthesis of the literature is warranted to facilitate a renewed and up-to-date understanding of the most common measures used to investigate this topic and analyse the extent to which the phenomenological side of this topic is captured, as well as how academics are coping with such demands.

\section{Universities in ferocious international competition}

In the last two decades the higher education sector has gone through a constant set of changes including a rapid growth in student numbers, a heavy focus on treating students as consumers, and an increasing pressure to generate research income which translates into an increasing and overwhelming workload for academics (Franco-Santos \& Doherty, 2017; Kinman \& Wray, 2014). Some authors argue that ideas of neoliberalism are now being applied to academia. This is to say, Polster (2016) suggests that the neoliberalisation of the academy assumes that universities have been transformed and gone through significant changes (e.g., structure, hierarchy, vision, values, practices) to adapt corporate models of management within university life. Gill (2016) argues that values pertaining to the labour market have now been adopted, and indeed invaded the academy with important effects that need to be analysed. Over the past 20 years, there has been a huge increase in student numbers in universities, triggering 
a global competition for recruiting international students, who represent a massive income for universities (Cantwell, 2015). As a result, this global competition has led to extreme pressure on academics to provide high-quality of teaching, bring in external income, improve the international outlook of their university, manage a heavy admin burden, and last but not least, it has put huge pressure on publishing research with "higher standards" - whatever this may mean (Kinman \& Wray, 2014). Among all the above-mentioned factors reported in the literature which impact academics’ physical and mental health, let us take as an example one of the most pressing challenges for academics - that of publishing. Considering these changes, it is not surprising that universities have developed mechanisms to ensure that this goal is fulfilled. For instance, the UK has in place the Research Excellence Framework (REF), which is a system to assess research production in all UK universities. According to Berg et al. (2016) these mechanisms can also be observed in Iceland (Evaluation System for Public Higher Education Institutions), Australia (Excellence in research dor Australia), Denmark (Den Bibliometriske Forskningsindikator) New Zealand (Performance-Based Research Fund) etc. While some academics may find these schemes useful for career progression (Edwards \& Roy, 2016) or as mechanisms to ensure the production of scientific knowledge (Watermeyer, 2016), other studies highlight the negative impact of such schemes leading to an increase on competition and the marketisation of the HE sector that compromises the quality of the research produced (Watermayer, 2016). According to Albatch (2012), this type of strategies in universities have one main goal - to be ranked in the first places based on international comparisons of global universities and attract more students. Unfortunately, science has also revealed that these types of excessive demands and rigorous assessment procedures are 
worryingly linked to high levels of stress, depression, anxiety and other mental health problems among academics (Bell, Rajendran \& Theiler, 2012; Fernández-Armesto, 2009, Mark \& Smith, 2012; Shepherd \& Edelman, 2009, Peake, 2016). It is clear that the volume and intensity of work for academics has dramatically increased over the last decades (Franco-Santos \& Doherty, 2017; Kinman, 2008). However, this does not come without a price to pay.

\section{Mental Health and Well-being in Academia}

Burnout is a state of mental and/or physical exhaustion caused by excessive and prolonged work stress (Maslach \& Schaufeli, 1993), whilst stress is defined as an "individual perceiving external demands as being beyond his or her ability to cope with such demands” (Yim et al., 2017, p. 6). According to Karimzadeh et al. (2017), mental health is used for describing "the cognitive and emotional levels of well-being as well as lack of psychological disorder” (p. 4497). In fact, positive psychology defines mental health as “one’s ability to enjoy life, create balance between daily activities and attempt to achieve psychological well-being” (p. 4498). The World Health Organisation on the other hand uses the term well-being to define mental health as "a state of well-being in which an individual realises his or her own abilities, can cope with the normal stresses of life, can work productively and is able to make a contribution to his or her community” (WHO, 2018). Specialised literature suggests that well-being varies greatly upon the perception of individuals, which in turn, makes it quite subjective (Proctor \& Tweed, 2016) and this is precisely why it is important to explore the personal lived experiences of academics. This has led psychologists to use the term subjective well-being (SWB), which refers to how people evaluate their lives considering three main factors, namely: life satisfaction, positive emotions and lack of negative emotions (Diener, 2000; Klug \& Maier, 
2015), but how are these elements affected by the university environment? While some research reveals that academics report high levels of satisfaction which lead them to thrive in university environments (Khalid, Irshad \& Mahmood, 2012; Rothman et al., 2011), a growing body of research also reveals that the university environment has a serious negative impact on academics' physical and mental health including an increasing trend for chronic burnout (Guthrie et al., 2017; Padilla \& Thompson, 2016), high level of stress (Richards, Andrew, \& Levesque-Bristol, 2016; Winefield \& Jarret, 2001), high job dissatisfaction (Barkhuizen et al., 2014), high work-life conflict (Hogan, Hogan, \& Hodgins, 2016), poor physical health (Nicholson, Fuhrer \& Marmot, 2005) and low productivity (Ford, Cerasoli, Higgins, \& Decesare, 2011). On the other hand, there are a number of factors in the university environment which can be perceived as stressors, which according to Monroe and Slavich (2016), are those external factors cognitively appraised by the individual “...to see if it poses a threat to their wellbeing” (p. 567). Factors which are perceived by the individual as threatening are regarded as stressors (Clark, 2012). Some of the stressors which have been found to impact academic staff include, ranking and constant competition (Ogbonna \& Harris, 2004), teaching (Kinman, 2014), supervising (Sun, Wu, \& Wang, 2011), undertaking research (Richards, Andrew, \& Levesque-Bristol, 2016), heavy workload and long hours (Flaxman, Ménard, Bond, \& Kinman, 2012), short-term contracts, increased student numbers (Kinman, 2008; Kinman \& Wray, 2013), and lack of recognition (Makikangas, Mauno, Selenko, \& Kinnune, 2019). Interestingly but worryingly, in some cases mental health problems found in academics outnumber those cases found in the general population. Winefield et al. (2008) found that 50\% of Australian academics were at risk of psychological illnesses compared to only $19 \%$ found in the general 
population. These findings are further supported by those from Kinman and Wray (2013), who found the same tendency in the UK. If these factors keep playing a role in academics' everyday life, they can initiate and/or may exacerbate mental health problems in the form of psychological distress (Andrew \& Wilding, 2004), which, in its chronic from, can lead to longterm disabling effects (Dewa et al., 2007; Lucas \& Diener, 2008).

Taken together, empirical studies show a multidimensional phenomenon affecting university academics, which should be included in the international agenda - just like the marketization of higher education and global competition. Academic staff mental health must be investigated with a view to ascertaining not only the levels of general health and well-being prevalent in universities across the world, but also what the main stressors are, how academics are coping with such extreme demands, and how researchers are investigating this phenomenon. Interestingly, a quick search in Google Scholar revealed no recent studies investigating the strategies that universities have in place to support the mental health of academic staff. Although some efforts have been made to support mental health of university staff, -for example in the UK the Health and Safety Executive strategy (Cousins et al., 2014), or the Organisational Multi-level Program in Australia (Pignata \& Winefiled, 2015)- these programs work only at a local level and not all universities are included. As a result, findings from this study have strong potential to inform targeted interventions with a view to improving the well-being of academic staff in addition to contributing to the international debate on this topic. Hopefully, this will lead to more studies in this respect across the globe with the hope that empirical evidence can help change policymakers’ mindset (i.e., valuing money/social 
recognition over mental health), and inform policymakers' decisions regarding the way in which universities work nowadays and how they can create safer environments for academics.

\begin{abstract}
Aims
This literature review aims to analyse international scientific research that has investigated how academics' mental health is negatively impacted by the higher education institution environment. In order to analyse such impact, it is necessary to focus our analysis on negative factors that hinder good mental health, such as stress, burnout and generally poor psychological health. These data are necessary to inform health-related interventions, educational policy, staff training and future research. The present review seeks to address the following questions:
\end{abstract}

(1) What is known about mental health within university teaching staff specifically related to well-being, burnout and stress?

(2) What are the most commonly used instruments/measures to investigate academics' mental health?

(3) What evidence in the literature is there that is related to the perceptions and lived experiences of academic staff with regards to well-being, burnout and stress?

(4) What are the main factors/stressors reported by academics that appear to influence their mental health and well-being?

(5) What are the main coping strategies used by academic staff to face academic demands?

\title{
Method
}


A literature review is characterised by its capacity to summarise the current knowledge in a specified field by selecting published papers that meet specific criteria according to the main aim of the study (Oxman 1994; Eriksson \& Lindstrom 2006). This systematic review was conducted in accordance with the PRISMA (Figure 1) guidelines (Moher, Liberati, Tetzlaff, \& Altman, 2009). A systematic search of electronic databases was conducted (ERIC, PsycINFO, PsycARTICLES, Scopus, Google Scholar and ProQuest) including a combination of terms (i.e., using Boolean operators) Wellbeing, well-being, well being, mental health, burnout, stress, university academics, teaching staff, lecturers, senior lecturers, professors, faculty, perceptions, stressors, lived experiences, coping strategies. The search was limited to scientific papers published in English and published in international peer-reviewed journals to ensure robustness of conclusions (Dunkin, 1996; Oxman, 1994). In order to maintain a reasonable scope for the study, we only analysed studies focusing on mental health specifically, including psychological well-being, burnout or stress among academics conducted within the last 10 years (2009-2019). This decision was based on three factors: fundamental changes in the global demands placed on academics over the last decade (Kinman, 2014), an emerging body of research focusing on investigating emotions in academics (Salimzadeh Saroyan \& Hall, 2017), and an existing review by Watts and Johnson (2011) of studies conducted prior to 2011. We also reviewed reference lists in the articles selected to retrieve additional potential papers. Retrieved studies were first screened for duplication, then by title and abstract, and finally as full text articles.

\section{Inclusion/exclusion criteria}


Given the aims of this study, studies that reported empirical data on the measurement and association between well-being, stress, burnout, negative indicators of psychological health, stressors, coping strategies and lived experiences were included.

\section{Databases}

To reflect the inter-disciplinary nature of this topic, search engines covering research in psychology, education and social sciences were interrogated (see Figure 1).

\section{Data Extraction}

Data was extracted from eligible studies using a data extraction template developed for this review (see Table 1 in appendix).

Figure 1 A PRISMA flow diagram of the process of selection and retention of eligible studies (based on Tai, Ng \& Lim, 2019)

\section{Figure one around here}

\section{Results}

Results from the manual and electronic searches were combined to reveal a total of 1339 papers. Titles and abstracts were reviewed with duplicates and non-English language articles being excluded, after which 30 papers met the inclusion criteria, and were subjected to full text review for final data extraction. 
What is known about mental health within university teaching staff specifically related to wellbeing, burnout and stress?

Findings from the studies confirm that academic staff experience high levels of stress and burnout with limited, but not circumstantial, evidence that staff experience low well-being. Our analysis revealed that most of the literature places an important emphasis on investigating two specific psychological constructs - namely, stress and burnout - to better understand how the academic environment affects staff's mental health. Eleven studies (39\%) focused on burnout whilst 17 (60\%) studies focused on stress and only three (11\%) investigated both variables together. Psychological well-being was the focus for seven (23\%) studies only, and it was found that this term is often used interchangeably with mental well-being or well-being alone, although the psychological well-being concept is frequently included in a broader definition of well-being. There were only nine (30\%) studies that investigated the main stressors, whilst worryingly, there were only three studies found in this review (Darabi, Macaskill \& Reidy, 2017a; Talbot \& Mercer, 2018; Mohamed \& Abed, 2017) that investigated the coping mechanisms used to face academic demands. Certainly, this gap warrants further investigation.

The studies reviewed reveal a keen interest with exploring levels of stress, burnout and, to a lesser extent, well-being in light of a number of other variables. Findings show the inclusion of a range of other variables to investigate mental health, such as: self-efficacy, empowerment, emotional intelligence, spirituality, job satisfaction, self-confidence, introversion/extraversion personality traits, transformational leadership, work-related quality of life, work engagement, job demands and resources, effective commitment, physical health, life satisfaction, 
absenteeism, work-life balance, work-life conflict, work pressure, work autonomy, admin procedure fairness, organisational commitment, social support, hope, optimism, gratitudes, self-efficacy and sense of coherence. Specifically, there was an interesting and unique study that investigated how stress and burnout are closely associated to physical health-related variables (Dreyer, Dreyer \& Ranking, 2010) such as physical illness, coronary risks, biochemical functioning, and lung functional capacity. This study has offered ground-breaking evidence regarding the close link between mental health negatively impacting physical health. This link should be investigated further.

Regarding the knowledge and understanding we have in this field so far, there seems to be an agreement that academic staff experience high levels of stress and burnout and low levels of well-being. Studies reviewed reveal that intense job demands tend to trigger high levels of stress (Boyd, et al., 2011; Darabi, Macaskill \& Reidy, 2017b; Simons, Munnik, Frantz \& Smith, 2019) and burnout (Zábrodská, Mudrák \& Šolcová, 2018). However, in an interesting study, Bell, Rajendran and Theiler (2012) found that usual job demands and pressure made no difference to well-being. Nevertheless, job threats (i.e., redundancy) did increase the level of ill-being and decreased well-being (Bell, Rajendran \& Theiler, 2012). Studies seem to confirm that high intensity job demands lead to high levels of burnout, which in turn trigger low levels of work engagement and organisational commitment (Bezuidenhout \& Cilliers, 2010; Barkhuizen, Rothmann \& Van de vijver, 2014). High levels of stress seem to trigger problems with delivering an effective community service (i.e., public lectures, seminars, debates) as part of academics’ socially responsible role (Usoro \& Etuk, 2017) and can predict lower life 
satisfaction, lower positive effect, poorer mental health and higher negative effect (Darabi, Macaskill \& Reidy, 2017b). However, staff with high levels of psychological well-being tend to report low levels of burnout (Sahni \& Deswal, 2015).

There is some evidence to suggest that young staff report higher levels of burnout (Chen et al., 2014) and stress compared to older staff (Osumah, 2017), which is consistent with other studies (Ishaq \& Mahmood, 2017; Slišković \& Seršić, 2011) that found that junior faculty (i.e., low ranking academics, such as lecturers and senior lecturers) seem to report higher levels of stress compared to professors. However, contradictory evidence suggests that younger staff experience low levels of burnout (Sahni \& Deswal, 2015). Moreover, Chalghaf, Azaiez and Elarbi (2014) found that higher ranking staff report higher levels of burnout. However, Akinmayowa and Kadiri (2014) and Darabi, Macaskill and Reidy (2017b) found that academic rank did not make a statistically significant difference in the stress experienced by staff. Interestingly, less teaching experience was associated with high levels of burnout (Sahni \& Deswal, 2015), with some evidence showing that staff working in the private sector are more stressed that their counterparts in the public sector. In the same vain, Ishaq and Mahmood (2017) found that private sector staff feel less empowered, which was associated with poorer well-being. However, these findings must be interpreted with caution, given the small sample size used. Other studies showed that levels of stress do not seem to be influenced by gender, department/faculty or years of working experience (Adebiyi, 2013; Akinmayowa \& Kadiri, 2014), but Slišković and Seršić (2011) found that women reported higher levels of stress compared to men. According to Kumar (2015) more experienced staff (e.g., aged 45+) seem to 
have become used to stressful situations and reported low levels of stress. Whilst high levels of burnout are associated with low job satisfaction (Kumar, 2015), high levels of stress seem to trigger low levels of life satisfaction (Darabi, Macaskill \& Reidy, 2017b; Sawhney \& Bansal, 2013). Malik and Tariq (2015) found that when leaders provide autonomy, encouragement and support to academics, higher levels of well-being and low levels of stress are observed.

At a more personal level, Salami (2011) found that stress, personality and social support were associated with burnout, but causality could not be established. Introverts have been shown to display higher levels of burnout when compared to extroverts (Sahni \& Deswal, 2015). High levels of occupational stress lead to less emotional intelligence, lower sense of self-efficacy (El-Sayed, El-Zeiny \& Adeyemo, 2014) and less ability to manage emotions in the workplace (Bowen, Rose \& Pilkington, 2016). Marriage, however, seems to be a protective factor from stress (Akinmayowa \& Kadiri, 2014; El-Amin, 2013), with married people reporting lower levels of stress compared to single people. Highly stressed and emotionally exhausted staff tend to report more physical symptoms, such as fatigue, backache and headache (Dreyer, Dreyer \& Ranking, 2010; El-Amin, 2013; Khalil, Omar \& Dawood, 2014; Mohamed \& Abed, 2017), which seem to be prevalent means through which stress is expressed. Optimism is positively associated to satisfaction with life (Darabi, Macaskill \& Reidy, 2017b).

What are the most commonly used instruments/measures to investigate academics' mental health? 
The review of the literature revealed a dominance of positivist over interpretative approaches to investigate this topic (see Table 1 in appendix). By far, the most common instrument used to investigate mental health was the Maslach Burnout Inventory, which measures burnout with a range of other instruments to measure stress (e.g., the Occupational Stress Scale, the Perceived Stress Scale, the Stress Prevalence Questionnaire, the Job stress Questionnaire etc.) and well-being (e.g., The Warwick-Edinburgh Mental Well-being Scale, PGI General Wellbeing Measure, The Ryff Scale of Psychological Well-Being etc.). In one study (Osumah, 2017), the author developed their own instrument, whilst in two studies (Usoro \& Etuk, 2017 and El-Amin, 2013) the authors did not clarify whether the instruments were adapted or newly created, posing challenges related to the validity and reliability of those findings which should be further confirmed. Our analysis reveals a wide variety of instruments used to measure different constructs to address the main aims of the studies (e.g., the School Participant Empowerment Scale, Spirituality Assessment Scale, Organizational Climate Inventory etc.), which did not allow the identification of common patterns.

What evidence in the literature is there that is related to perceptions and lived experiences of academic staff with regards to well-being, burnout and stress?

Most of the studies focused on measuring different variables from a positivist perspective, neglecting the role that personal experience and individual perception plays in well-being. From all the studies analysed, there were only two studies that actually explored the lived experiences of academic staff from a phenomenological perspective. Talbot and Mercer's (2018) study focused on staff views on the factors impacting emotional well-being, and found 
that social interactions (i.e., interacting with students) and a positive attitude towards their job (i.e., finding a meaningful impact in the profession, appreciating the workplace culture, having positive family life and having the desired job) seem to be protective factors for emotional well-being. On the other hand, they found that staff use a few strategies to boost their emotional well-being such as: cognitive reappraisal, social-self comparison, problem-directed action, recalling positive events and showing gratitude. Darabi, Macaskill and Reidy (2017a) investigated stressors and coping strategies used by academics. There were many stressors identified including but not limited to heavy workloads, administrative burdens, time pressures. Participants reported that the main coping strategies used were support from colleagues and time management. While these studies offer essential evidence to better understand how academics are impacted, the sample size used suggests further investigation may be required.

What are the main factors/stressors reported by academics which appear to influence their mental health and well-being?

From the nine studies exploring factors which influence academics’ mental health, interesting commonalities could be found. The main factor that seems to influence academics' well-being relate to an excessive amount of allocated workload (Darabi, Macaskill \& Reidy, 2017a); ElSayed, El-Zeiny \& Adeyemo, 2014; Mohamed \& Abed, 2017; Simons, Munnik, Frantz \& Smith, 2019; Salami, 2011), which was the most cited factor by participants. This was followed by: job insecurity (Darabi, Macaskill \& Reidy, 2017a); Ishaq \& Mahmood, 2017; Simons, Munnik, Frantz \& Smith, 2019); increasing number of hours and demand for professional growth (Ishaq \& Mahmood, 2017); and lack of organisational support, such as limited 
promotion opportunities, unreasonable expectations and lack of support to obtain research funding (Darabi, Macaskill \& Reidy, 2017a); El-Sayed, El-Zeiny \& Adeyemo, 2014; Khalil, Omar \& Dawood, 2014; Slišković \& Seršić, 2011). Additional factors included inadequate resources (El-Sayed, El-Zeiny \& Adeyemo, 2014; Salami, 2011), time pressure (Salami, 2011; Zábrodská, Mudrák \& Šolcová, 2018) and poor social recognition (Slišković \& Seršić, 2011). Interestingly, other factors were the lack of independence and perceived powerlessness (Simons, Munnik, Frantz \& Smith, 2019). However, this was only true for black academics in this study. Finally, students’ misbehaviour was mentioned in one study only (Salami, 2011)

What are the main coping strategies used by academic staff to face academic demands? There were only three studies that investigated the coping strategies used to face academic demands. Talbot and Mercer (2018) found that staff use a few strategies to boost their emotional well-being, which in turn help them to face work-related demands, such as cognitive reappraisal, social-self comparison, problem-directed action, recalling positive events and showing gratitude. Mohamed and Abed (2017) found that accepting responsibility, seeking social support and using cognitive/emotional reappraisal (i.e., giving a different meaning to stressful situations) were the most frequently used strategies by participants. Darabi, Macaskill and Reidy (2017a) found that support from colleagues and time management were the most commonly used strategies. Overall, these studies have certainly expanded our understanding from a phenomenological perspective, but the limited sample size and locations used open new avenues for further research.

\section{Discussion}


The main finding to emerge from this systematic review is that there is compelling evidence to suggest that academic staff experience high levels of stress and burnout with subtle, but important, signs that show that staff experience low well-being in higher education institutions which is consistent with previous studies in the field (Barkhuizen, Rothmann, \& Van de Vijver, 2014; Kinman \& Johnson, 2019). A striking finding is that there are virtually no studies (only two found in this review) that investigate the lived experiences and perceptions of staff from a phenomenological perspective, whilst most of the evidence analysed places an important emphasis on investigating two specific psychological constructs - namely, stress and burnout - and, to a lesser extent, well-being from a positivist perspective. Another remarkable finding relates to the lack of research focusing on investigating how staff cope with stressors in an effective way, coupled with limited studies focusing on ascertaining the main stressors affecting staff's mental health. These findings open new avenues for future research necessary to improve our knowledge and understanding of the other stressors that are reported by academics, and more importantly, how the impact on their mental health is mediated by individual perceptions. Investigating the main stressors and how academics perceive such stressors (and how they cope with them), is of utmost importance, given the subjective nature of psychological constructs such as well-being, stress and burnout, which are all terms grounded on the perception of the individual (Ryff, 2014). Our study revealed a number of variables that scholars have instigated, including, but not limited to, self-efficacy, empowerment, emotional intelligence, spirituality, job satisfaction, self-confidence, transformational leadership, work-related quality of life, and work engagement. Investigating these variables is consistent with other literature highlighting the need to consider a range of 
factors to ascertain how mental health is being influenced by personal and environmental factors (Fontinha, Easton \&Van Laar, 2019; Hall et al., 2016).

Our analysis revealed that current research, seems to focus on limited aspects of the whole spectrum of mental health, with very limited research providing a holistic perspective on this important phenomenon, which is consistent with findings elsewhere (Salimzadeh, Saroyan \& Hall, 2017). There seems to be a tendency to use the Maslach Burnout Inventory to measure burnout, but this inventory is limited to people-oriented occupations and has limited applicability across cultures according to Milfont et al. (2008). On the other hand, we view the use of a diversity of instruments to measure stress as favourable since these have been adapted and validated with different populations, which suggests that cultural adaptations have taken place. This diversity suggests that scholars consider the role of cultural variables in academics’ stress, but they still neglect the role of individual perception, which is essential when measuring psychological constructs (Judge \& Klinger, 2008). However, when it comes to measuring wellbeing, there still seems to be a prevailing confusion in using the concepts of mental health, well-being and psychological well-being, interchangeably, which all possess some challenges when measuring this construct (Dagenais-Desmarais \& Savoie, 2011). Despite the efforts of the scientific community, the understanding of this concept remains heterogeneous (Harris \& Cameron, 2005). Additional research is necessary to reach a better understanding of how to measure well-being. 
Results showed that, overall, our knowledge and understanding of how academics view and experience academic demands from a personal stance is worryingly limited, and this field remains substantially under-researched. Whilst most of the research has helped us understand that academics are indeed experiencing high levels of stress and burnout and low levels of wellbeing with quantitative measures, there is the need to actually hear from first-hand, how academics live, feel or experience job-related demands -which is a concern found in other studies (Salimzadeh, Saroyan \& Hall, 2017). Future studies should focus on investigating the individual experience of academics which will contribute to our current body of empirical evidence and which has the potential to shed light on the cognitive mechanisms underlying personal perception and its role in dealing with academic demands.

Overall, our analysis suggests that excessive workload, job insecurity and lack of support to obtain research funding are the main stressors that have deleterious effects on academics' mental health. Findings from this study are consistent with previous research findings that highlight heavy administrative burden, lack of organisational support and limited social recognition as particularly hazardous to well-being (Barkhuizen, Rothman \& Van de Vivjer, 2014; Guthrie et al., 2017; Torp, Vinje, Haaheim-Simonsen, 2016). However, our study revealed that only a limited number of studies actually investigate stressors reported by academics. Hence, our understanding is limited. Further research should indeed focus on the main stressors with a view to ascertaining how additional stressors may be jeopardising academics' mental health and more importantly, how these can be addressed in universities (Kinman \& Johnson, 2019; Watts \& Robertson, 2011). 
Some evidence seems to suggest that university staff seems to be exposed to more challenging stressors compared to other fields. Research in Australia found that academics work for longer periods of time compared to other professions (Kinman, 2014). In fact, Kinman goes on to highlight that academics experience higher rates of psychological distress compared to other professions such as company managers, clerical/secretarial and sales personnel. Watts and Robertson (2011) found that levels of emotional exhaustion in university staff were pretty similar to "high risk" groups such as physicians and nurses. Whilst Barkhuizen and Rothman (2008) report that university staff receive less support from the organisation compared to 20 other occupational groups, Winefield (2000) provides evidence that shows that academics report higher levels of stress compared to other occupations, such as engineering employees, prison officers, teachers, transport workers and general university staff. Overall, findings consistently show faculty staff report higher stress levels than other university staff and the general public (see Winefield et al., 2003) and that according to Kinman (2014), academic staff seems to be in greater need for psychological support compared to community samples. In fact, recent studies (Edwards, Guppy \& Cockerton, 2017; Ford et al., 2011; Häusser et al., 2010) have found that the consequences of stress in academics, are very similar to the consequences observed on performance employees and on psychological and physical health-related occupations.

Worryingly, our analysis revealed that scholars may be interested in how academics are getting mentally ill. However scholars do not seem to be interested in how academics are facing job- 
related demands. Based on the extremely limited evidence we found, it seems that cognitive reappraisal is the most common strategy used to cope with job demands, but we do not know if other populations use it or how academics developed such strategy. Future research should focus on investigating what coping strategies academics use to better understand the cognitive mechanisms underlying this and other strategies, and their role in mediating the impact of stressors in mental health.

\section{Limitations}

Whilst the findings from this study clearly contribute to the international literature, this study has several limitations. There could be other studies housed in other databases that we did not include, as well as important studies that may have been published in languages other than English. The inclusion of additional terms in the search stage (i.e., anxiety, depression, etc.), could potentially yield additional studies related to mental health. Nevertheless, we firmly believe that our findings have shed light on important gaps in the literature that are now open for further investigation.

\section{Conclusions and Practical implications.}

There is compelling evidence that academics' mental health across the world is being negatively impacted by the current global demands of the higher education sector. Academic burden is real and is making staff mentally ill. Academics are impacted at a psychological and physical level that could importantly, reduce productivity. We do not seem to listen to how 
academics’ job may be having psychological implications. Universities should start valuing their staff's well-being over money and international recognition. Institutions should have policies in place to balance job demands and avoid jeopardising academics’ mental health. There seems to be an important need to create targeted psycho-educational interventions in universities across the world to support academics who have already experienced high levels of stress, burnout or low levels of well-being. Employers should open up spaces for staff to be listened to and feel supported. 


\section{Reference List}

Adebiyi, D. R. (2013). Occupational stress among academic staff of Ekiti state university, AdoEkiti. European Scientific Journal, 9(4).

Akinmayowa, J. T., \& Kadiri, P. A. (2016). Stress Among Academic Staff in a Nigerian University. Covenant Journal of Business and Social Sciences, 6(1).

Altbach, P. G. (2012). The globalization of college and university rankings. Change: The Magazine of Higher Learning, 44(1), 26-31.

Andrews, B., \& Wilding, J. M. (2004). The relation of depression and anxiety to life-stress and achievement in students. British journal of psychology, 95(4), 509-521.

Barkhuizen, N., Rothmann, S., \& van de vijver, F. J. (2014). Burnout and work engagement of academics in higher education institutions: Effects of dispositional optimism. Stress and Health, 30(4), 322-332.

Bell, A. S., Rajendran, D., \& Theiler, S. (2012). Job Stress, Wellbeing, Work-Life Balance and Work-Life Conflict Among Australian Academics. E-Journal of Applied Psychology, 8(1).

Berg, L. D., Huijbens, E. H., \& Larsen, H. G. (2016). Producing anxiety in the neoliberal university. The Canadian Geographer/le géographe canadien, 60(2), 168-180.

Bezuidenhout, A., \& Cilliers, F. V. (2010). Burnout, work engagement and sense of coherence in female academics in higher-education institutions in South Africa. SA Journal of Industrial Psychology, 36(1), 1-10.

Boyd, C. M., Bakker, A. B., Pignata, S., Winefield, A. H., Gillespie, N., \& Stough, C. (2011). A longitudinal test of the job demands-resources model among Australian university academics. Applied psychology, 60(1), 112-140.

Cantwell, B. (2015). Laboratory management, academic production, and the building blocks of academic capitalism. Higher Education, 70(3), 487-502.

Chalghaf, N., Azaiez, F., \& Elarbi, B. (2014). Triggers of burnout among Tunisian teachers at higher institutes of sport and physical education. IOSR Journal of Humanities and Social Science, 19(7), 70-77.

Chen, W. S., Haniff, J., Siau, C. S., Seet, W., Loh, S. F., \& Abd, M. H. (2014). Burnout in Academics: An empirical study in private universities in Malaysia. The International Journal of Social Sciences and Humanities Invention, 1(2), 62-72. 
Clarke, S. (2012). The effect of challenge and hindrance stressors on safety behavior and safety outcomes: A meta-analysis. Journal of occupational health psychology, 17(4), 387.

Cohen, R. B. (2018). 12 The new international division of labor, multinational corporations and urban hierarchy. Urbanization and urban planning in capitalist society, 7.

Cousins, R., Mackay, C. J., Clarke, S. D., Kelly, C., Kelly, P. J., \& McCaig, R. H. (2004). 'Management standards' work-related stress in the UK: Practical development. Work \& Stress, 18(2), 113-136.

Dagenais-Desmarais, V., \& Savoie, A. (2012). What is psychological well-being, really? A grassroots approach from the organizational sciences. Journal of Happiness Studies, 13(4), 659-684.

Darabi, M., Macaskill, A., \& Reidy, L. (2017a). A qualitative study of the UK academic role: positive features, negative aspects and associated stressors in a mainly teaching-focused university. Journal of Further and Higher Education, 41(4), 566-580.

Darabi, M., Macaskill, A., \& Reidy, L. (2017b). Stress among UK academics: Identifying who copes best. Journal of Further and Higher Education, 41(3), 393-412.

Dewa, C. S., Lin, E., Kooehoorn, M., \& Goldner, E. (2007). Association of chronic work stress, psychiatric disorders, and chronic physical conditions with disability among workers. Psychiatric services, 58(5), 652-658.

Diener, E. (2000). Subjective well-being: The science of happiness and a proposal for a national index. American psychologist, 55(1), 34.

Dreyer, S., Dreyer, L. I., \& Rankin, D. M. (2010). The Health and Wellbeing of Staff Members at a Tertiary Institution in New Zealand. ICHPER-SD Journal of Research, 5(1), 4553.

Duderstadt, J. J. (2009). Changing university missions and profiling in the United States: some lessons learned in the New World.

Duderstadt, J. J. (2009). A university for the 21st century. University of Michigan Press.

Dunkin, M. J. (1996). Types of errors in synthesizing research in education. Review of Educational Research, 66(2), 87-97.

El-Amin, M. A. M. M. (2013). Occupational stress among female academic staff at universities in Khartoum State. Ahfad Journal, 30(1), 29. 
El-Sayed, S. H., El-Zeiny, H. H. A., \& Adeyemo, D. A. (2014). Relationship between occupational stress, emotional intelligence, and self-efficacy among faculty members in faculty of nursing Zagazig University, Egypt. Journal of Nursing Education and Practice, 4(4), 183.

Edwards, J. A., Guppy, A., \& Cockerton, T. (2007). A longitudinal study exploring the relationships between occupational stressors, non-work stressors, and work performance. Work \& Stress, 21(2), 99-116. http://dx.doi.org/10.1080/02678370701466900

Edwards, M. A., \& Roy, S. (2017). Academic research in the 21st century: Maintaining scientific integrity in a climate of perverse incentives and hypercompetition. Environmental engineering science, 34(1), 51-61.

Eriksson, M., \& Lindström, B. (2006). Antonovsky’s sense of coherence scale and the relation with health: a systematic review. Journal of epidemiology \& community health, 60(5), 376-381.

Eurofound (2019), Working Conditions and Workers' Health, Publications Office of the European Union, Luxembourg. Retrieved on May $4^{\text {th }}$, 2020 from: https://www.eurofound.europa.eu/sites/default/files/ef_publication/field_ef_document lef18041en1.pdf

Fernández-Armesto, F. 2009. 1492: The year our world began. London, UK: Bloomsbury.

Flaxman, P. E., Ménard, J., Bond, F. W., \& Kinman, G. (2012). Academics'experiences of a respite from work: Effects of self-critical perfectionism and perseverative cognition on postrespite well-being. Journal of Applied Psychology, 97, 854-865.

Fontinha, R., Easton, S., \& Van Laar, D. (2019). Overtime and Quality of Working Life in Academics and nonacademics: The Role of Perceived Work-Life Balance. International Journal of Stress Management, 26, 173-183.

Ford, M. T., Cerasoli, C. P., Higgins, J. A., \& Decesare, A. L. (2011). Relationships between psychological, physical, and behavioural health and work performance: A review and meta-analysis. Work \& Stress, 25(3), 185-204.

Franco-Santos, M., \& Doherty, N. (2017). Performance management and well-being: a close look at the changing nature of the UK higher education workplace. The International Journal of Human Resource Management, 28(16), 2319-2350. 
Franco-Santos, M., \& Doherty, N. (2017). Performance management and well-being: a close look at the changing nature of the UK higher education workplace. The International Journal of Human Resource Management, 28(16), 2319-2350.

Gill, R. (2016). Breaking the silence: The hidden injuries of neo-liberal academia. Feministische Studien, 34(1), 39-55.

Guthrie, S., Lichten, C. A., Van Belle, J., Ball, S., Knack, A., \& Hofman, J. (2017). Understanding mental health in the research environment.

Gutland, C. (2018). Husserlian phenomenology as a kind of introspection. Frontiers in Psychology, 9, 896.

Hall, L. H., Johnson, J., Watt, I., Tsipa, A., \& O’Connor, D. B. (2016). Healthcare staff wellbeing, burnout, and patient safety: a systematic review. PloS one, 11(7), e0159015.

Harris, G. E., \& Cameron, J. E. (2005). Multiple dimensions of organizational identification and commitment as predictors of turnover intentions and psychological well-being. Canadian Journal of Behavioural Science, 37(3), 159-169.

Häusser, J. A., Mojzisch, A., Niesel, M., \& Schulz-Hardt, S. (2010). Ten years on: A review of recent research on the job demand-control (-support) model and psychological well-being. Work \& Stress, 24(1), 1-35. http://dx.doi.org/10.1080/02678371003683747

Hogan, V., Hogan, M., \& Hodgins, M. (2016). A study of workaholism in Irish academics. Occupational Medicine, 66(6), 460-465.

Holtz, P., \& Odağ, Ö. (2018). Popper was not a Positivist: Why Critical Rationalism Could be an Epistemology for Qualitative as well as Quantitative Social Scientific Research. Qualitative Research in Psychology, 1-24.

Hurtado, S., Alvarez, C. L., Guillermo-Wann, C., Cuellar, M., \& Arellano, L. (2012). A model for diverse learning environments. In Higher education: Handbook of theory and research (pp. 41-122). Springer, Dordrecht.

Ishaq, R., \& Mahmood, A. (2017). Relationship between Job Stress and Employee BurnoutThe Moderating Role of Self-Efficacy for University Teachers. Journal of Research \& Reflections in Education (JRRE), 11(2).

Karimzadeh, M., Rostami, M., Teymouri, R., Moazzen, Z., \& Tahmasebi, S. (2017). The association between parental mental health and behavioral disorders in pre-school children. Electronic physician, 9(6), 4497. 
Khalid, S., Irshad, M. Z., \& Mahmood, B. (2012). Job satisfaction among academic staff: A comparative analysis between public and private sector universities of Punjab, Pakistan. International journal of Business and Management, 7(1), 126.

Khalil, A., T. Omar, \& E. Dawood. (2014) "Perceived work-related stressors and its relationship with the physiological and psychological well being of nursing faculty members." J Educ Pract 5.39: 64-75.

Kinman, G. (2008). Work stressors, health and sense of coherence in UK academic employees. Educational Psychology, 28(7), 823-835.

Kinman, G. (2014). Doing more with less? Work and wellbeing in academics. Somatechnics, 4(2), 219-235.

Kinman, G., \& Johnson, S. (2019). Special section on well-being in academic employees. International Journal of Stress Management, 26(2), 159.

Kinman, G. \& Wray, S. (2013). Higher Stress: A Survey of Stress and Wellbeing among Staff in Higher Education, London: UCU Publications

Kinman, G., \& Wray, S. (2014). Taking its toll: rising stress levels in further education. University and College Union.

Klug, H. J., \& Maier, G. W. (2015). Linking goal progress and subjective well-being: A metaanalysis. Journal of Happiness Studies, 16(1), 37-65.

Kumar, S. (2015). Influence of spirituality on burnout and job satisfaction: A study of academic professionals in Oman. South Asian Journal of Management, 22(3), 137.

Lucas, R. E., \& Diener, E. (2008). Subjective well-being. Handbook of emotions, 471484.

Makikangas, A., Mauno, S., Selenko, E., \& Kinnunen, U. (2019). Toward an Understanding of a Healthy Organizational Change Process: A Three- Wave Longitudinal Study Among University Employees. International Journal of Stress Management, 26, 204-212

Malik, S. Z., \& Tariq, S. (2015). Relationship of Transformational Leadership, Psychological Well-Being and Self-Efficacy: A Mediation Analysis in University Faculty. Journal of Quality and Technology Management, 11(2), 93-109.

Mark, G., \& Smith, A. P. (2012). Occupational stress, job characteristics, coping, and the mental health of nurses. British journal of health psychology, 17(3), 505-521.

Maslach, C. \& Schaufeli, W.B. (1993), Historical and conceptual development of burnout. In W.B. Schaufeli, C. Maslach \& T. Marek (eds.), Professional Burnout: Recent Developments in Theory and Research, New York: Taylor \& Francis. 
Milfont, T. L., Denny, S., Ameratunga, S., Robinson, E., \& Merry, S. (2008). Burnout and wellbeing: Testing the Copenhagen burnout inventory in New Zealand teachers. Social indicators research, 89(1), 169-177.

Mohamed, S. A., \& Abed, F. Job stressors, Burnout Levels and Coping Strategies among Faculty Members and Assistants: a comparative Study.

Moher, D., Liberati, A., Tetzlaff, J., Altman, D. G., \& Prisma Group. (2009). Reprintpreferred reporting items for systematic reviews and meta-analyses: the PRISMA statement. Physical therapy, 89(9), 873-880.

Monroe, S. M., \& Slavich, G. M. (2016). Psychological stressors: overview. In Stress: Concepts, cognition, emotion, and behavior (pp. 109-115). Academic Press.

Nicholson, A., Fuhrer, R. \& Marmot, M. (2005). Psychological Distress as a predictor of CHD events in men: The effect of persistence and components of risk. Psychosomatic Medicine, 67, 522-530

Ogbonna, E., \& Harris, L.C. (2004). Work Intensification and Emotional Labour among UK university lecturers: An exploratory study. Organisation Studies, 25(7), 1185-1203.

Osumah, O. A. (2017). Gender and age differences in the experience of occupational stress among university lecturers in Edo State, Nigeria. Gender and Behaviour, 15(3), 96189626.

Oxman, A. D. (1994). Systematic reviews: checklists for review articles. Bmj, 309(6955), 648651.

Padilla, M. A., \& Thompson, J. N. (2016). Burning out faculty at doctoral research universities. Stress and Health: Journal of the International Society for the Investigation of Stress, 32, 551-558.

Peake, L. (2016). Critical Reflections on Mental and Emotional Distress in the Academy. ACME: An International E-Journal for Critical Geographies, 15(2).

Pignata, S., \& Winefield, A. H. (2015). Stress-reduction interventions in an Australian university: A case study. Stress and Health, 31(1), 24-34.

Polster, C. (2016). Academic insecurity and privatization in western universities. Routledge Handbook of the Sociology of Higher Education, 94.

Proctor, C., \& Tweed, R. (2016). Measuring eudaimonic well-being. In Handbook of eudaimonic well-being (pp. 277-294). Springer, Cham. 
Rae, D. (2010). Universities and enterprise education: responding to the challenges of the new era. Journal of small business and enterprise development, 17(4), 591-606.

Richards, K. A. R., Levesque-Bristol, C., Templin, T. J., \& Graber, K. C. (2016). The impact of resilience on role stressors and burnout in elementary and secondary teachers. Social Psychology of Education, 19(3), 511-536.

Rothman, S., Kelly-Woessner, A., \& Woessner, M. (2010). The still divided academy: How competing visions of power, politics, and diversity complicate the mission of higher education. Rowman \& Littlefield Publishers.

Ryff, C. D. (2014). Psychological well-being revisited: Advances in the science and practice of eudaimonia. Psychotherapy and psychosomatics, 83(1), 10-28.

Sahni, M., \& Deswal, A. (2015). Burnout among teacher educators with respect to biographical, psychological and organizational variables. International Journal of Management and Social Sciences Research, 4(1), 1-11.

Salami, S. O. (2011). Job stress and burnout among lecturers: Personality and social support as moderators. Asian Social Science, 7(5), 110.

Salimzadeh, R., Saroyan, A., \& Hall, N. (2017). Examining the Factors Impacting Academics' Psychological Well-Being: A Review of Research. International Education Research, 5(1), 13-44.

Sawhney, N., \& Bansal, S. (2013). Life satisfaction of professional college teachers in relation to their stress level. Indian Journal of Health and Wellbeing, 4(2), 272-277.

Schaufeli, W. B. (2013). What is engagement? In Employee engagement in theory and practice (pp. 29-49). Routledge.

Shepherd, R. M., \& Edelman, R. J. (2009). The Interrelationship of Social Anxiety with Anxiety, Depression, Locus of Control, Ways of Coping and Ego Strength amongst University Students. College Quarterly, 12(2), n2.

Shin, J. C., \& Jung, J. (2014). Academics job satisfaction and job stress across countries in the changing academic environments. Higher Education, 67, 603-620.

Shirazi, F., Rezvani, S., Haghighi, N., \& Farzamfar, E. (2014). The relationship between mental health disorders with anxiety and depression in mothers of children. Cheshmandaz Amin in Applied Psychology, 1(1), 37-44.

Simons, A., Munnik, E., Frantz, J., \& Smith, M. (2019). The profile of occupational stress in a sample of health profession academics at a historically disadvantaged university in South Africa. South African Journal of Higher Education, 33(3), 132-154. 
Slišković, A., \& Seršić, D. (2011). Work stress among university teachers: Gender and position differences. Archives of Industrial Hygiene and Toxicology, 62(4), 299-307.

Sun, W., Wu, H., \& Wang, L. (2011). Occupational stress and its related factors among university teachers in China. Journal of Occupational Health, 53(4), 280-286.

Tai, K. L., Ng, Y. G., \& Lim, P. Y. (2019). Systematic review on the prevalence of illness and stress and their associated risk factors among educators in Malaysia. PloS one, 14(5), 410-432

Talbot, K., \& Mercer, S. (2018). Exploring University ESL/EFL Teachers’ Emotional WellBeing and Emotional Regulation in the United States, Japan and Austria. Chinese Journal of Applied Linguistics, 41(4), 410-432.

Torp, S., Vinje, H. F., \& Haaheim-Simonsen, H. K. (2016). Work, wellbeing and presence among researchers. International Journal of Mental Health Promotion, 18, 199-212.

Usoro, A. A., \& Etuk, G. R. (2016). Workload Related Stress and Job Effectiveness of University Lecturers in Cross River and Akwa Ibom States, Nigeria. Asian Journal of Social Sciences and Management Studies, 3(1), 34-41.

Watermeyer, R. (2016). Impact in the REF: issues and obstacles. Studies in Higher Education, 41(2), 199-214.

Watts, J., \& Robertson, N. (2011). Burnout in university teaching staff: A systematic literature review. Educational Research, 53(1), 33-50.

Winefield, A. H., \& Jarrett, R. (2001). Occupational Stress in University Staff. International Journal of Stress Management, 8, 285-298.

Winefield, A. H., Gillespie, N., Stough, C., Dua, J., Hapuarachchi, J., \& Boyd, C. (2003). Occupational stress in Australian university staff: Results from a national survey. International Journal of Stress Management, 10(1), 51.

Winefield, T., Boyd, C., Saebel, J., \& Pignata, S. (2008). Update on national university stress study. Australian Universities' Review, The, 50(1), 20.

World Health Organization. (2018). Mental health atlas 2017. World Health Organization.

Yusoff, R. M., \& Khan, F. (2013). Stress and burnout in the higher education sector in Pakistan: A systematic review of literature. Research Journal of Recent Sciences ISSN, (2277), 2502.

Zábrodská, K., Mudrák, J., Šolcová, I., Květon, P., Blatný, M., \& Machovcová, K. (2018). Burnout among university faculty: The central role of work-family conflict. Educational Psychology, 38(6), 800-819 


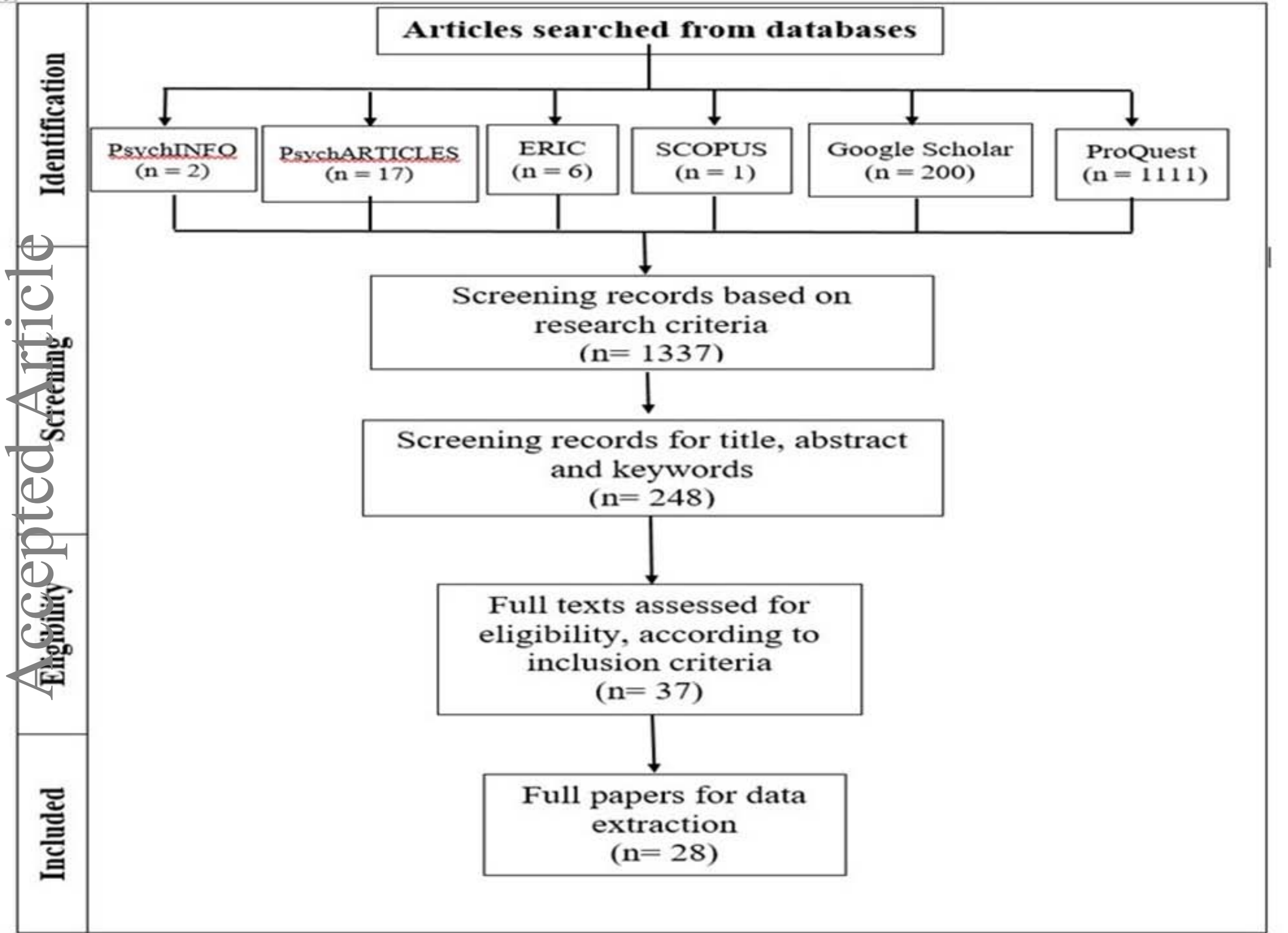

